\title{
Rethinking Global Innovation Strategy: Emerging Market Perspectives
}

\author{
Yuting Qiu ${ }^{1} \&$ Yiyang Fan ${ }^{2}$ \\ ${ }^{1,2}$ Business School, University of Shanghai for Science and Technology, Shanghai, China \\ Correspondence: Yuting Qiu, Business School, University of Shanghai for Science and Technology, Shanghai, No. \\ 516, Jungong Rd.,China. Tel: +86-13764551385. E-mail: yting.qiu@gmail.com
}

Received: June 13, 2013

Accepted: July 5, 2013

Online Published: July 6, 2013

doi:10.5430/bmr.v2n3p33

URL: http://dx.doi.org/10.5430/bmr.v2n3p33

\begin{abstract}
The prosperity of emerging markets is challenging the traditional global innovation strategy. The unique characteristics - market fragmentation, demand heterogeneity, shortage of resources and inadequate infrastructure - of emerging markets impel their emergence as a source of innovation and disruptive force. Only the innovation with attributes of accessibility, acceptability, affordability and sustainability can match these characteristics and contribute to the rest of world. After revisiting the reality and dilemmas in today's world, it is suggested that the essence of innovation should be solving everyday problems, eradicating poverty and hunger, and helping the people attain an inclusive-and-sustainable future. Therefore, this paper develops a grand revolution paradigm and provides a top-down-and-bottom-up approach to explore the untapped "Fortune at the Bottom of the Pyramid".
\end{abstract}

Keywords: Emerging market, Innovation strategy, Reverse innovation

\section{Introduction}

Global economic climate is in a state of uncertainty. The economic recovery has so far been sluggish and uneven across different regions. Growth remains stagnant or even negative in developed countries, whereas far more robust in emerging economies such as China and India. Emerging world is expected to account for as much as two-thirds of the world's GDP growth in 2015. The rapid urbanization in the emerging markets accelerates the rise of a well-to-do middle class in those countries. But the emerging world is still suffering from huge income gap which limits most customers' purchasing power, for example GNI per capita (PPP) in U.S. $(\$ 48,820)$ vs. China $(\$ 8,390)$ (World Bank World Development Indicators, 2012). And these emerging markets constitute a mega customer base which is more than $70 \%$ of the global population. How to win these potential customers in emerging markets? It is a huge challenge as well as opportunity for both western MNCs and the companies in emerging world.

Innovation, as a major force in economic growth, is expected to develop prescriptions for this stagnant world. The importance of innovation has been identified ever since the Age of Schumpeter. For decades, most researches have focused on its promoting effects on growth. But to solve today's problem of worldwide unbalanced development, there is an urgent need to discover new perspectives and practices in innovation strategy. Innovation can not only boost economic growth but also can solve everyday problems, eradicate poverty and hunger, and help the people attain an inclusive-and-sustainable future. And even more important, it needs a mind-set change when we understand the dynamics of emerging markets which used to be called the Bottom of Pyramid (BOP) or BOP markets.

Nearly ten years ago, Prahalad and Hammond (2002) and Prahalad and Hart (2002) have identified BOP markets as an untapped but potential profitable consumer base, and indicated that MNCs should extend their business scope to serve poor consumers. Thus C.K. Prahalad utilized external constraints to build an innovation sandbox approach and provided some success stories to show that it's important to develop an ecosystem rather than a product in BOP markets (Prahalad, 2006; Prahalad, 2012; Reficco \& Márquez, 2012).

Trend of Globalization provides a solution for MNCs to test their new products, services, business models and expand their scale of production in emerging markets and for "emerging" companies to leverage high-tech low-cost abilities to disrupt global competition (Williamson \& Zeng, 2004; Williamson, 2005; Williamson, 2010). Gorodnichenko et al. analyzed firm-level data from 27 emerging economies and found that globalization has a positive impact on innovation in emerging markets (Gorodnichenko, Svejnar \& Terrell, 2010). And increasing empirical evidence shows that firms in emerging economies have successful innovation practices in local markets and even threaten the western MNCs in advanced markets (Zeng \& Williamson, 2007; Williamson \& Zeng, 2008). 
But Karnani (2007) argued that it's costly to serve consumers in emerging markets because of their geographical fragmentation and cultural heterogeneity. Immelt and Govindarajan (2009) also pointed out that products developed for consumers in rich markets would not satisfy consumers in poor market and the approach of globalization would not be applicable to all cases. They suggest innovation should deeply immerse in consumers' lives to develop unique solution, and put forward an approach of reverse innovation which regards emerging markets as incubation centres for radical innovation.

As the emerging markets are changing the traditional value equation, it requires the corporations and policy makers to transcend technological or business perspectives of innovation and focus on value creation and delivery. More importantly, global innovation strategy derived from one-way approach is not compatible with current context. Thus this paper try to find the reality that must be tackled, explore the very source that sparks imagination, and rethink the essence and processes of innovation therein. Then we develop a grand revolution paradigm and provide a top-down-and-bottom-up approach to reach the untapped "Fortune at the Bottom of the Pyramid".

\section{Shift the global economy's center of gravity}

The global economy is experiencing a seismic shift. The developing countries' emergence as an economic force is one of the most major context of our times. Particularly, the BRIC countries (Brazil, Russia, India, and China) play an important role in the current global economy configuration. According to a report entitled "World in 2050" by $\mathrm{PwC}$, China is projected to equivalent to the US in purchasing power parity (PPP) by 2017 and in market exchange rates (MER) by 2027. India could become the third largest economic giant by 2050. Brazil is expect to overtake the 4th place ahead of Japan, and Russia should surpass Germany to become the largest European economy by 2020 in PPP terms and by 2035 in MER terms (PwC, 2013).

\subsection{The rise of Emerging Markets}

The situation in advanced economies is more precarious with the risks of sinking into a prolonged slump, while unemployment is still high and it will take time to fully recover from crisis. But it doesn't mean that the advanced countries are getting poorer, but high levels of income per capita and rapidly aging population will limit their growth. In contrast, the emerging countries have been the world's fastest-growing economies and their consumers will become the most prospective buyers of products and services from advanced countries. While the traditional industrial markets become over-saturated, companies have turned to these lucrative markets for their future growth.

The collective largest emerging market economies are referred as the E7(China, India, Brazil, Russia, Indonesia, Mexico and Turkey) while G7 is the finance group consisting of seven wealth advanced economies such as US, Japan, Germany, UK, France, Italy and Canada. According to PwC's prediction, the E7 countries will be more than $50 \%$ larger than the G7 countries based on GDP at MERs by 2050 and around 75\% larger in PPP terms. But currently, the E7 is just under $50 \%$ of the G7 economies when measured by GDP at MERs and just over $80 \%$ of the size of the G7 based on GDP in PPP terms (PwC, 2013).

\subsection{The Characteristics of Emerging Markets}

As emerging markets evolved from the periphery to the economic center of gravity, emerging market economies (EMEs) have become the main engine of global economic growth and the steady build-up of advanced countries should depend on the fast-growing demand from emerging markets. Therefore it is needed to find the realities of emerging markets and explore their unique characteristics, which are distinctive from traditional industrialized markets.

\section{1) Market Fragmentation}

A major characteristic of emerging markets is that markets are local, fragmented, and dispersed. This phenomenon is quite distinct in those countries with vast territory and wide range of haves and have-nots such as China and India. These economies are enduring lopsided development. And people in each fragmented market are indicative of multiple ethnicity, cultures, capabilities, and demands. Especially, the tradition and culture are often at variance with the needs of modern living.

These fragmented markets are composed of mega consumers who are referred as the "bottom-of-the-pyramid" community, living below the official poverty level and currently served by small and unorganized owner-managed enterprises (Sheth, 2011). Even worse, market environment and business competition are glutted with widening inequality. Under this condition, accessibility and affordability may be more important for competitive advantage than a superior product or service with limited access.

2) Demand Heterogeneity 
World-wide liberalization of trade and investment, bilateral trade agreements, and regional economic integrations such as the EU, ASEAN and Mercosur have been heating up global competition. Worldwide consumers have been offered with unprecedented choices of products or services, which stimulate their big aspiration. There're lots of examples that the most innovative and technically superior products win the markets and earn high profits, such as iPhone and kindle.

But in emerging markets, the situation is somewhat different. With respect to the market fragmentation, the diversity concerning accessibility and affordability tends to be various in urban and rural markets. In the areas with limited access to market and poor purchasing power, consumers have to buy unbranded products or services. So the heterogeneity in emerging market is both driven by demand diversity and by resource constraints (Sheth, 2011).

\section{3) Shortage of resources}

Seventy percent of the world's population live in emerging economies, but many of them are still suffering from inadequate supply of resources, such as electricity and fresh water. Not only people's living and consumption are constrained by shortage of resources, but also the whole society's production and exchange are affected. For example, the chronic shortage of energy, irregular supply of raw materials, and lack of skilled labor make production inconsistent thereby pushing up the costs. Similarly, lack of scale and unsounded financial supporting mechanisms increase the transaction costs.

Consequently, with a large population and limited resources, the people in emerging markets have to innovate to strive against the dilemma, and this is expressed in every strand of society: by those grassroots innovators; by entrepreneurs; and by small, medium, and large corporations. With respect to the shortage of resources, resource-conserving perspective casts a light on the future of product innovation, distribution and usage. Innovating low-cost, affordable products and services with decent performance is consumption efficiency in emerging markets.

\section{4) Inadequate infrastructures}

As the result of history of pre-industrialization, an important characteristic of emerging markets is inadequate infrastructures. Infrastructure contains not only transportation systems including physical roads, logistics, and storage, water and power supplies but also public institutions, such as schools, post offices and hospitals. It also means lack of market transaction agents, such as point-of-sale terminals, and basic banking support, and lack of communication and information technologies, such as telephones and electricity (Sheth, 2011).

Although such infrastructure is now widespread throughout much of the industrialized world, it is absent in emerging markets. Consumers in many rural areas have no access to telephone, television or network, even worse, no access to modern transportations. Therefore, innovation is necessary in the way products are sold, distributed, and financed (Khanna, Palepu, \& Sinha, 2005). Creating nontraditional channels and innovative access to consumers becomes the key element in the success of a product and service. All of these add up to a fundamental rethinking of the business model in emerging markets (Ramamurti \& Singh, 2009).

\section{Reverse the Diffusion of Innovation}

It's expected that the collective size of domestic demand in emerging markets will be larger than that of developed countries. In traditional approach of "Glocalization", a combination of "globalization" and "localization", products or services were originally developed for rich customers of west, then lightly adapted or knocked out certain expensive and high-tech features to target customers in emerging markets. But MNCs find that the scaled-down variants of those developed for rich countries cannot meet the needs of the price sensitive customers in emerging markets. And it is not always a simple way to develop products with drastically lower costs and localized features just by tinkering with existing designs (Prahalad, 2005).

Reverse innovation is coined to overcome such puzzle. The term of "Reverse innovation" is introduced by Dartmouth professors Vijay Govindarajan and Chris Trimble and GE's Jeffrey R. Immelt, and refers to an innovation seen or be adopted first in emerging or poor economies before trickling up to rich countries (Immelt, Govindarajan, \& Trimble, 2009; Ramamurti, 2009). The process of reverse innovation is quite opposite to the approach of Glocalization. Due to the lower affordability in emerging or poor economies, reverse innovation first focuses on developing products and services which address the need with decent quality but at an ultra-low price, that is, a $50 \%$ solution at a $5 \%$ price. At the beginning, such solution providing only $50 \%$ quality was unattractive in the rich world, but eventually, performance of these products started rising to the point that it became attractive within the rich world (Govindarajan, Kopalle \& Danneels, 2011).

The application of these solutions is not limit to the emerging market where they originated. And the ideas and 
technologies can create new markets and segment in mature markets even disrupting the older value network (Christensen \& Raynor, 2003). This new innovation strategy casts new lights on the companies that have been stuck in fierce competition. The promising economies which currently deem as "emerging" attract the global innovation gravity to unlock their potential purchasing power.

At the same time, it inspires many interesting as well as intricate puzzles for current innovation theory, such as where innovations occur and why they diffuse reversely. To understand the potential of disruptive market effects, it forces us to rethink the essence of innovation, what types of innovation accord with the characteristics of emerging markets, and why such innovation can contribute to the rest of world.

\subsection{Starting from the laggards}

Innovation was once assumed to equate with technological innovation and originate in the developed countries. In the product cycle theory developed by Vernon (1966), the US was viewed as technology leader and the source of innovations that targeted high-income consumers. In addition, innovations advanced in developed countries are supposed to diffuse horizontally among developed countries then downward to developing countries (Vernon, 1979).

But with the world's economic center of gravity shifted, in coming decades, two-thirds of world GDP growth is likely to occur in developing countries rather than developed countries. The growth of the emerging markets has led to the emergence of new middle-class consumers who are first-time buyers of everything from personal care products to smart digital gadgets, household appliances to automobiles and homes. These middle class consumers are highly valued as lead users and closely resemble their counterparts in advanced countries. Their needs are of strategic significance to companies everywhere. Both local and global innovations are stimulated to meet these demands.

Besides those on the very top of economic pyramid of emerging markets, there are large-scale and untapped markets where consumers are hovering around poverty level. Especially in populous countries like China and India, these economies are classic cases of dichotomy where millions of billionaires and the impoverished community co-exist, and their unique needs and demands are completely opposite.

In his seminal work Diffusion of Innovations, Everett M. Rogers (2003) has classified consumers into five adopter categories: innovators, early adopters, early majority, late majority and laggards on the basis of innovativeness. The innovators or early adopters act as the entry point to bigger share of markets, and the laggards act as the end point of adoption lifecycle and totally ignored in entire innovation process.

Lead users such as consumers in advanced countries were always viewed as early adopters of cutting-edge innovations and generally less price sensitive (Von Hippel, 1986, Geoffrey Moore, 2002). And their role in diffusing innovations is co-creator that companies can work with them to launch new products or services to target at mainstream consumers. By contrast, the laggards in the right tail of the diffusion curve, are extremely value conscious, satisfy themselves with 'good enough' quality, and costly to reach and serve. And all these profiles are typical of the mass market consumers in emerging economies.

This dilemma spawns local companies in emerging economies that have access to international resources, such as capital, technology and suppliers, to innovate for local solutions, then for the unbalanced global markets (Williamson \& Zeng, 2009; Ramamurti, 2009). New products or services developed entirely in emerging markets for emerging markets are likely to disrupt developed markets and create new business opportunities. The nascent phenomenon reconfigures the process of innovation - developed countries are no longer viewed as the locus where new products or ideas are conceived and commercialized but instead take on the role of recipients of innovation that developed in and for emerging countries (Hart \& Christensen, 2002; Govindarajan \& Ramamurti, 2011; Dossani \& Kenney, 2009).

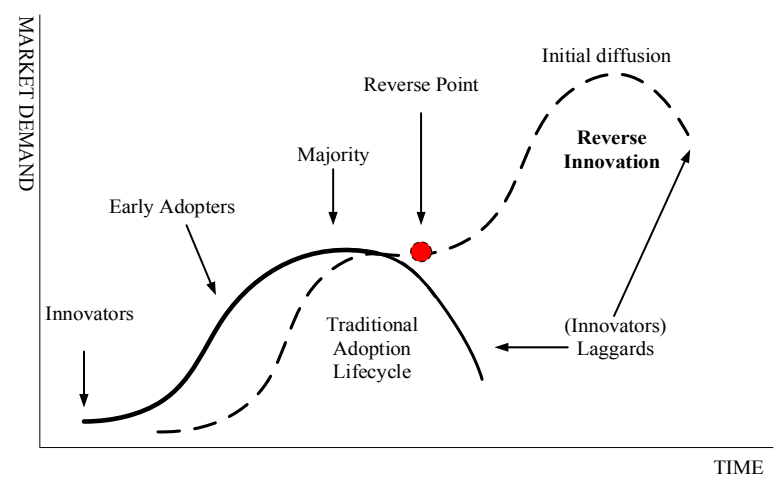

Figure 1. Reverse the Diffusion of Innovation 
As the growth of emerging markets, the needs of laggards which were ignored by academics and practitioners for long, currently draw the attention of global players. Just as lead users can be leveraged to diffuse an innovation to mainstream users, reverse innovation can be used to turn laggards into innovators (see Figure 1). The laggards at the bottom of pyramid, rather than lead users on the very top of pyramid, will become a more advantageous source of innovation.

\subsection{The nature of innovation in EMs}

The most important dimension on which emerging markets differ from advanced markets is the per capita income of average consumers. The huge income gap splits consumers in advanced markets and emerging markets into two ends of the innovation adoption curve. And as a result of lower purchasing power, the mass market in emerging or poor countries requires products with groundbreaking price-performance features, creating opportunities and challenges for affordable and accessible innovations.

More importantly, the characteristics - market fragmentation, demand heterogeneity, shortage of resources and inadequate infrastructure - of emerging markets are radically different from the traditional advanced markets. All these puzzles hinder the development of emerging markets, as well as cause a decline in the living standards and happiness of people therein. There is no way to success but to solve these puzzles. And to contend with these unique features, it is required to rethink the fundamental role of innovation in emerging markets. Innovation should function as a powerful problem solver rather than the engine of economic growth. And to be a problem solver, innovation in emerging markets would appreciate the values that matter most to consumers: accessibility, acceptability, affordability and sustainability.

- Accessibility is perceived as channels that how products distribute and sell. Increasing accessibility can tackle the issues of market fragmentation and inadequate infrastructure.

- Acceptability is perceived as conditions under which products or services are used. Concerning differences in multidimensional measure of cultural, geographic and economic distance between regions and countries, acceptability means value creation and delivery to tackle the issue of demand heterogeneity.

- Affordability is perceived as price-performance ratio. Innovation with decent performance and much lower cost can fulfill the demands and needs in untapped markets and create much more consumer value.

- Sustainability represents environment-friendly. Shortage of resource in emerging markets appreciates the sustainable pattern of consumption more valuable in helping maintain a balanced and long-lasting development.

The four attributes of innovation derive from a consumer value perspective based on the unique characteristics of emerging markets. And their core role is to help corporations create value for consumers in emerging markets, identify what they want and need and uncover new wants and needs. This means not only ensuring that customers are aware of products or services, but also ensuring that products or services are accessible, acceptable and affordable to them. Moreover the products or services should deliver a positive value that help people attain an inclusive-and-sustainable future. Therefore, the nature of innovation in emerging markets is demand fulfillment, value creation and market development.

\subsection{Why innovations diffuse reversely}

As technological change and economic liberalization flatten the world, it's creating an opportunity for innovations specifically in and for emerging markets to migrate to advanced markets. For example, local companies like Huawei in ICT industries, Embraer in aircraft manufactures and Suzlon in wind energy industries are all born in emerging economies and embracing the world as global players.

Since in Vernon's product cycle theory, innovations would diffuse from developed to less developed countries, it forwards an interesting question that why would innovation diffuse in the counterintuitive direction? And if the large differences such as gaps in per capita income (Ghemawat, 2001) between poor and rich countries provide basis for local innovation in emerging markets, shouldn't the same reason inhibit the diffusion of innovations to developed countries (Govindarajan \& Ramamurti, 2011)?

Pressures or drivers? That is the question. Everett M. Rogers $(1983,2003)$ argued that five attributes of innovation - relative advantage, compatibility, complexity, trialability, observability - can explain between 49 and 87 percent of the variance in the rate of adoption. He found that greater relative advantage, compatibility, trial ability, observability, and less complexity will speed up an innovation's rate of adoption. Relative advantage can be measured in economic terms, as well as convenience, and satisfaction. Compatibility is what consistent with the existing values and past experiences. Trialability represents less uncertainty to consumers and complexity is 
perceived as difficult to understand and use.

In response to the value creation and market development, corporations in emerging markets come up with frugal innovations and disruptive innovations (Christensen \& Raynor, 2003) to improve the price-performance features, making products or services much more acceptable, accessible, affordable and sustainable especially for the BOP community. Moreover, innovation developed in and for emerging market exhibits an advantage which differs from innovation developed in advanced markets, that is, it's capability to meet the multiple demands of wide cross-section of society. There are many rich consumers like lead users in advanced markets, but still much more mainstream consumers who resemble the mega consumers in emerging markets. That's the key point why innovation in and for emerging markets can trick up to advance markets. With the unique characteristics of accessibility, acceptability, affordability and sustainability which are accord with the five attributes of greater relative advantage, compatibility, trialability, observability, and less complexity, innovations once rooted in emerging markets are scattering their seeds on the fields of advanced markets.

\section{The Grand Revolution Paradigm}

The Economist's special issue on innovation in emerging markets, subtitled 'The world turned upside down,' claimed that 'the emerging world, long a source of cheap labor, now rivals the rich countries for business innovation' (The Economist, 2010). The emerging forces of developing countries affect the way that corporations innovate and manage innovation. At first, companies in emerging markets focus on indigenous innovations for accessible and affordable products or services, then what succeed based in local markets have a potential to become a global market opportunity.

Such examples have already happened in the pharmaceutical, automotive, solar and wind energy industries as well as in personal computers, consumer electronics and house appliances. Consequently, new generation of global corporations is rising from the emerging countries, including Tata, Lenovo, Infosys and Haier. And as emerging markets become core to a company's innovation strategy, the traditional thinking of "Think global, Act local" should be reversed as "Think local, Act global".

Therefore, concerning the essence of innovation creation, the role of EMs in innovation diffusion process and the importance of heterogeneity in business evolution, we put forward a grand revolution paradigm consisting of three cycles to point out how to think local and act global.

\subsection{Taking the needs of consumers as a starting point}

What's the reality? What products or services people really want and need and can afford? The superior-quality product with the latest technology embedded is a great luxury to most ordinary people, especially for the micro consumers in mega markets. There is no need to add but strip the products and services down to their essential elements. Therefore, it is a social responsibility maybe a more profitable way to deliver life-enhancing products and services across a much broader spectrum of the world's population.

That requires the practitioners take the needs of consumers as a starting point and work upwards (See the First cycle in Figure 2). Viewing the fragmented markets as an ecosystem and understanding interdependence of different market species, companies, social unions and governments can work together to discover bottlenecks and craft creative way to raise the life quality of billions of people.

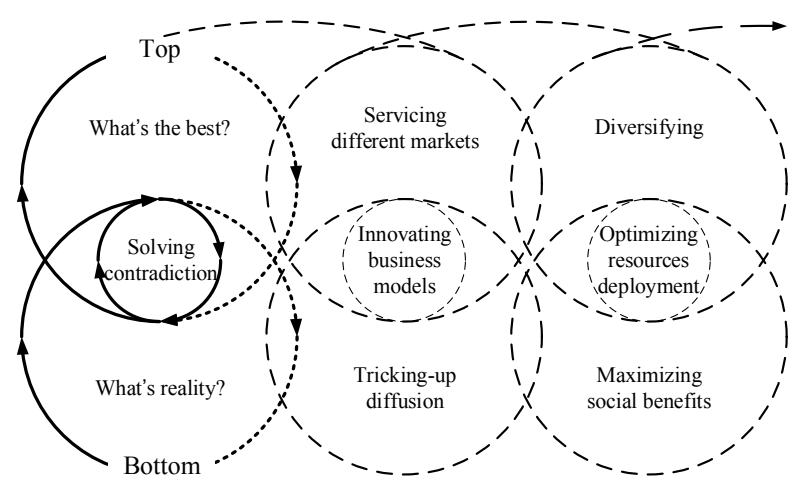

Figure 2. The Grand Revolution Paradigm 


\subsection{Rethinking entire business model}

Seeking emerging markets for inspiration, MNCs and local companies have learned how to reach different consumers, how to deal with scarcity and most importantly how to apply these lessons globally. Since the marginalized are going mainstream, the emerging and even poor world collectively represent a huge and untapped market. The entrepreneurs are trying to provide innovative products and services just because they see "fortune at the bottom of the pyramid" and the enormous potential of trickling-up diffusion (See the Second cycle in Figure 2).

As emerging markets are becoming drivers of fundamental and disruptive innovation, it involves not just redesigning products but also rethinking entire business system. The innovation capability has beyond the grasp of R\&D organizations. To serve radically different markets and consumers, it's the best way to empower the consumer to co-create business solutions that meet his or her most urgent and important needs. And the polycentric innovation is encouraged to explore the role of governments, corporations and individuals as drivers of innovation and provide prescriptions that lead to lasting progress and prosperity.

\subsection{The way to inclusive growth}

The people live in a planet but a dramatically diverse society. Cultural, demographical, economical, ethnic, geographical, linguistic, racial, religious and social diversity makes the world amazing and hard to achieve harmony. Therefore the role of inclusive growth comes to play. The inclusive growth implies proactive inclusion of all consumers with the ultimate goal of maximizing social benefits (See the Third cycle in Figure 2).

Now emerging markets have become hotbeds of innovation, spawning a large number of market-based affordable products and business innovations. But in many populous countries like China and India, the path to an inclusive-and-sustainable future is a long journey and full with obstacles. They have to battle growing pains in the process of economic development, such as great inequality and pollution of environment. But the primary task is still eradicating poverty and hunger. And two pragmatic approaches can achieve this goal. First, fully deploy social resources to target specific areas such as consumer literacy, micro-financing, and the supply of basic necessities. Second, encourage public-private partnership to focus on the societal needs of unserved markets on a sustainable long-term basis.

\section{Conclusion}

Three major revolutions - agricultural, industrial and information revolutions - in past centuries determined the course of history. Every revolution exhibits its own distinctive traits. For example, the Agricultural Revolution made it possible to meet the basic food needs of large population, the Industrial Revolution affected the production process disruptively, and the Information Revolution changed the way people think, understand and connect with the world. All in all, they as a whole create the modern society we live in today.

Innovation, as one of the key factors underpinning these revolutions, always find its direction from the wants and needs of ordinary people. The living standard of people in today has impressively improved ever since the old days, but there still are many dilemmas that micro consumers have to face and struggle with. The world is increasingly complex and dynamic-9 years aging (on average) in 2050, 70\% more urban (compared to $50 \%$ in 2012), and 50\% of population growth will be based in Africa. We are witnessing a grand revolution which engages to struggle the world out of mess and fulfill its sustainability obligations to meet the expectations of most ordinary people.

The rise of emerging markets contributes decisively to this revolution. Their ability to boot innovation in line with market requirements and to solve tough problems will be an indispensable advantage in today's world. And "the Fortune at the Bottom of the Pyramid" turns out to be not only the purchasing and manufacturing power but also the design and innovation capabilities. After revisiting the global innovation strategy from an emerging market perspective, it will suggest that a top-down-and-bottom-up innovation paradigm can be a win-win situation.

\section{Acknowledgements}

Financial support from NSSFC (13BJY021) and Academic Talent Development Program for Liberal Arts and Social Sciences, Shanghai Academic Degrees Committee (2012[13]) is gratefully acknowledged. Y. Qiu gratefully acknowledges the kindness and considerable mentoring provided by Prof. Y. Fan and the helpful suggestions and criticism from W. Ruan and Z. Ge. The research has also benefited from the support of China Shanghai Municipal Research Project of Education and Science 2011(B11041) and is also part of the Soft Science Research Program of the Shanghai Foundation for Development of Science and Technology, China (096921048). 


\section{References}

Christensen, C. M., \& Raynor, M. E. (2003). The innovator's solution: Creating and sustaining successful growth. Harvard Business School Press.

Dossani, R., \& Kenney, M. (2009). Service provision for the global economy: the evolving Indian experience. Review of policy research, 26(1-2), 77-104. http://dx.doi.org/10.1111/j.1541-1338.2008.00370.x

Ghemawat, P. (2001). Distance still matters. Harvard business review, 79(8), 137-147.

Gorodnichenko, Y., Svejnar, J., \& Terrell, K. (2010). Globalization and innovation in emerging markets. American Economic Journal: Macroeconomics, 2(2), 194-226. http://dx.doi.org/10.1257/mac.2.2.194

Govindarajan, V., Kopalle, P. K., \& Danneels, E. (2011). The effects of mainstream and emerging customer orientations on radical and disruptive innovations. Journal of Product Innovation Management, 28(s1), 121-132. http://dx.doi.org/10.1111/j.1540-5885.2011.00865.x

Govindarajan, V., \& Ramamurti, R. (2011). Reverse innovation, emerging markets, and global strategy. Global Strategy Journal, 1(3-4), 191-205. http://dx.doi.org/10.1002/gsj.23

Hart, S. L., \& Christensen, C. M. (2002). The great leap. Driving innovation from the base of the pyramid. Sloan Management Review, 44(1), 51-56.

Immelt, J. R., Govindarajan, V., \& Trimble, C. (2009). How GE is disrupting itself. Harvard Business Review, 87(10), 56-65.

Karnani A. 2007. The mirage of marketing to the Bottom of the Pyramid: How the private sector can help alleviate poverty. California Management Review 49(4): 90-111. http://dx.doi.org/10.2307/41166407

Khanna, T., Palepu, K. G., \& Sinha, J. (2005). Strategies that fit emerging markets. Harvard Business Review, 83(6), 63-76.

Moore, G. A. (2002). Crossing the chasm: Marketing and selling disruptive products to mainstream customers. HarperBusiness.

Paton, B., \& Halme, M. (2007). Bringing the needs of the poor into the BOP debate. Business Strategy and the Environment, 16(8), 585-586. http://dx.doi.org/10.1002/bse.606

Prahalad, C. K., \& Hammond, A. (2002). Serving the world's poor, profitably. Harvard business review, 80(9), 48-59.

Prahalad, C. Hart. S. (2002). The Fortune at the Bottom of the Pyramid. Strategy and Business, 26(1), 54-67.

Prahalad, C. K. (2005). The fortune at the bottom of the pyramid: eradicating poverty through profits. Philadelphia, PA: Wharton School Publishing.

Prahalad, C. K. (2006). The innovation sandbox. Strategy and Business, 44, 1-10.

Prahalad, C. K. (2012). Bottom of the Pyramid as a Source of Breakthrough Innovations. Journal of Product Innovation Management, 29(1), 6-12. http://dx.doi.org/10.1111/j.1540-5885.2011.00874.x

PwC Economics. (2013). World in 2050. The BRICs and Beyond: Prospects, challenges and opportunities. Retrieved from

http://www.pwc.com/en_GX/gx/world-2050/the-brics-and-beyond-prospects-challenges-and-opportunities.jhtml

Ramamurti, R. (2009). What have we learned about emerging-market MNEs? Emerging multinationals in emerging markets, 399-426. Cambridge, U.K.: Cambridge University Press. http://dx.doi.org/10.1017/CBO9780511576485.013

Ramamurti, R., \& Singh, J. V. (2009). Indian multinationals: Generic internationalization strategies. Emerging multinationals in emerging markets, 110-165. Cambridge, U.K.: Cambridge University Press. http://dx.doi.org/10.1017/CBO9780511576485.006

Reficco, E., \& Márquez, P. (2012). Inclusive networks for building BOP markets. Business \& Society, 51(3), 512-556. http://dx.doi.org/10.1177/0007650309332353

Rogers, E. M. (1983, 2003). Diffusion of innovations. 3rd ed. And 5th ed., New York, NY: Free Press.

Sheth, J. N. (2011). Impact of emerging markets on marketing: Rethinking existing perspectives and practices. Journal of Marketing, 75(4), 166-182. http://dx.doi.org/10.1509/jmkg.75.4.166 
The Economist. (2010, April 15). New masters of management: special report on innovation in emerging markets. The world turned upside down.

Vernon, R. (1966). International investment and international trade in the product cycle. Quarterly journal of economics, 80(2), 190-207. http://dx.doi.org/10.2307/1880689

Vernon, R. (1979). The product cycle hypothesis in a new international environment. Oxford bulletin of economics and statistics, 41(4), 255-267. http://dx.doi.org/10.1111/j.1468-0084.1979.mp41004002.x

Von Hippel, E. (1986). Lead users: a source of novel product concepts. Management science, 32(7), 791-805. http://dx.doi.org/10.1287/mnsc.32.7.791

Williamson, P., \& Zeng, M. (2004). Strategies for competing in a changed China. MIT Sloan Management Review, 45(4), 85-91. http://dx.doi.org/10.1007/978-3-540-34615-9_7

Williamson, P. J. (2005). Strategies for Asia's new competitive game. Journal of Business Strategy, 26(2), 37-43. http://dx.doi.org/10.1108/02756660510586328

Williamson, P., \& Zeng, M. (2008). How to meet China's cost innovation challenge. Ivey Business Journal, 72(3), $1-7$.

Williamson, P. J. (2010). Cost innovation: preparing for a 'value-for-money'revolution. Long Range Planning, 43(2), 343-353. http://dx.doi.org/10.1016/j.lrp.2009.07.008

Williamson, P., \& Zeng, M. (2009). Chinese multinationals: Emerging through new global gateways. Emerging Multinationals in Emerging Markets, 81-109. Cambridge, U.K.: Cambridge University Press. http://dx.doi.org/10.1017/CBO9780511576485.005

World Bank. (2012, Dec. 21). WDI World Development Indicators, GNI per capita ranking, Atlas method and PPP based, Retrieved from http://data.worldbank.org/data-catalog/GNI-per-capita-Atlas-and-PPP-table.

Zeng, M., Williamson P.J., (2007), Dragons at your door: how Chinese cost innovation is disrupting the rules of global competition, Boston, MA: Harvard Business School Press. 